\title{
Predicting complex acute wound healing in patients from a wound expertise centre registry
}

\author{
a prognostic study
}

\begin{abstract}
Author(s)
Ubbink, Dirk T; Lindeboom, Robert; Eskes, Anne M; Brull, Huub; Legemate, Dink A; Vermeulen, Hester
\end{abstract}

DOI

10.1111/iwj.12149

Publication date

2015

Document Version

Final published version

Published in

International Wound Journal

Link to publication

\section{Citation for published version (APA):}

Ubbink, D. T., Lindeboom, R., Eskes, A. M., Brull, H., Legemate, D. A., \& Vermeulen, H. (2015). Predicting complex acute wound healing in patients from a wound expertise centre registry: a prognostic study. International Wound Journal, 12(5), 531-536.

https://doi.org/10.1111/iwj.12149

It is not permitted to download or to forward/distribute the text or part of it without the consent of the author(s) and/or copyright holder(s), other than for strictly personal, individual use, unless the work is under an open content license (like Creative Commons).

If you believe that digital publication of certain material infringes any of your rights or (privacy) interests,

please let the Library know, stating your reasons. In case of a legitimate complaint, the Library will make the material inaccessible and/or remove it from the website. Please contact the library:

https://www.amsterdamuas.com/library/contact/questions, or send a letter to: University Library (Library of the University of Amsterdam and Amsterdam University of Applied Sciences), Secretariat, Singel 425, 1012 WP Amsterdam, The Netherlands. You will be contacted as soon as possible.
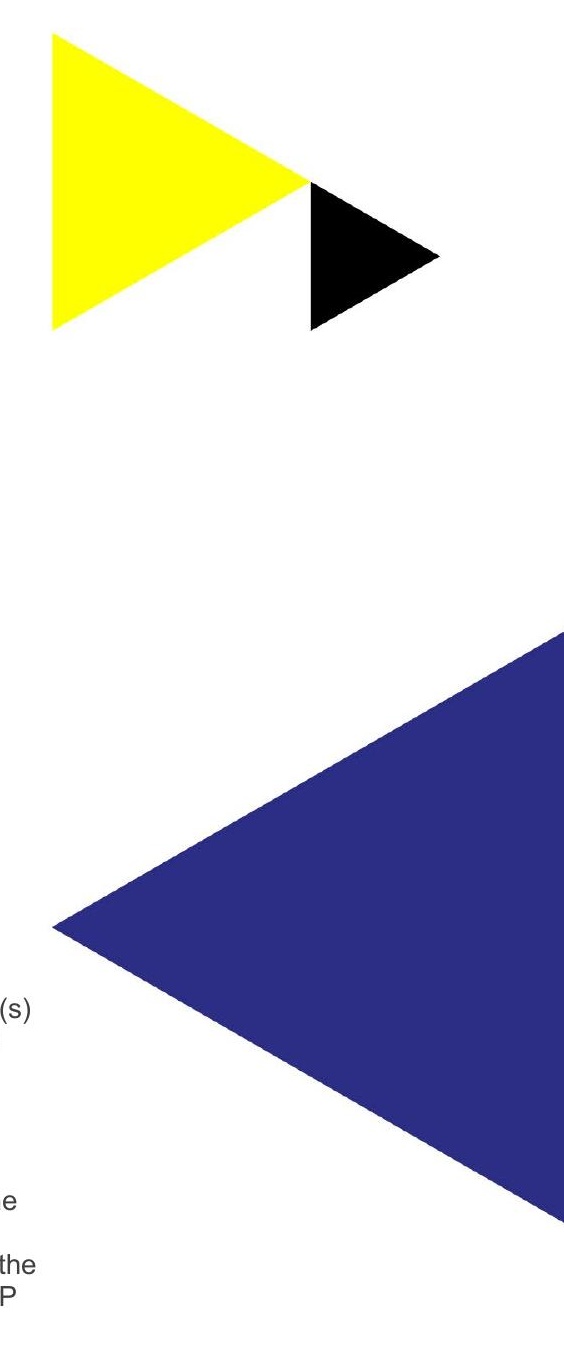


\title{
Predicting complex acute wound healing in patients from a wound expertise centre registry: a prognostic study
}

\author{
Dirk T Ubbink ${ }^{1,2}$, Robert Lindeboom ${ }^{3}$, Anne M Eskes ${ }^{4,5}$, Huub Brull ${ }^{6}$, Dink A Legemate ${ }^{2}$ \\ \& Hester Vermeulen ${ }^{1,5}$ \\ 1 Department of Quality Assurance \& Process Innovation, Academic Medical Center, University of Amsterdam, Amsterdam, the Netherlands \\ 2 Department of Surgery, Academic Medical Center, University of Amsterdam, Amsterdam, the Netherlands \\ 3 Department of Clinical Epidemiology, Biostatistics and Bioinformatics, University of Amsterdam, Amsterdam, the Netherlands \\ 4 Research Center Linnaeus Institute, Spaarne Hospital and Kennemer Gasthuis, Haarlem, the Netherlands \\ 5 Amsterdam School of Health Professions, University of Amsterdam, Amsterdam, the Netherlands \\ 6 Mitralis Expertise Centre for Wound Care, Heerlen, the Netherlands
}

\section{Key words}

Acute wounds; Prediction; Prognosis;

Wound expertise centre; Wound healing

\section{Correspondence to}

DT Ubbink

Department of Quality Assurance \& Process Innovation

Room A3-503

Academic Medical Center

Meibergdreef 9

P.O Box 22700

1100 DE Amsterdam

the Netherlands

E-mail: d.ubbink@amc.nl

doi: 10.1111/iwj.12149
Ubbink DT, Lindeboom R, Eskes AM, Brull H, Legemate DA, Vermeulen H. Predicting complex acute wound healing in patients from a wound expertise centre registry: a prognostic study. Int Wound J 2015; 12:531-536

\section{Abstract}

It is important for caregivers and patients to know which wounds are at risk of prolonged wound healing to enable timely communication and treatment. Available prognostic models predict wound healing in chronic ulcers, but not in acute wounds, that is, originating after trauma or surgery. We developed a model to detect which factors can predict (prolonged) healing of complex acute wounds in patients treated in a large wound expertise centre (WEC). Using Cox and linear regression analyses, we determined which patient- and wound-related characteristics best predict time to complete wound healing and derived a prediction formula to estimate how long this may take. We selected 563 patients with acute wounds, documented in the WEC registry between 2007 and 2012. Wounds had existed for a median of 19 days (range 6-46 days). The majority of these were located on the leg (52\%). Five significant independent predictors of prolonged wound healing were identified: wound location on the trunk [hazard ratio (HR) $0.565,95 \%$ confidence interval (CI) 0.405-0.788; $P=0.001]$, wound infection (HR $0.728,95 \%$ CI $0.534-0.991 ; P=0.044$ ), wound size (HR 0.993, 95\% CI 0.988-0.997; $P=0.001$ ), wound duration (HR 0.998, 95\% CI $0.996-0.999 ; P=0.005)$ and patient's age (HR 1.009, 95\% CI 1.001-1.018; $P=0 \cdot 020$ ), but not diabetes. Awareness of the five factors predicting the healing of complex acute wounds, particularly wound infection and location on the trunk, may help caregivers to predict wound healing time and to detect, refer and focus on patients who need additional attention.

\section{Introduction}

Some wounds heal quickly and uneventfully, whereas others take much longer and require more effort to heal. Wound healing may be prolonged in the presence of chronic diseases such as diabetes, arterial or venous insufficiency or pressure ulcers. Also, wounds with an acute aetiology, that is, after trauma or surgery, may be prone to delayed wound healing and may therefore need advanced professional care to achieve closure (1). Nowadays, these so-called complex acute wounds are increasingly treated by teams of specialised physicians and

\section{Key Messages}

- knowing which wounds will heal poorly helps determining the wounds that need special attention and care

- for chronic wounds several factors have been shown to predict (impaired) wound healing, but not for acute wounds, originating after trauma or surgery

- in this study, wound size, duration, infection, location on the trunk and the patient's age predicted (impaired) 
healing of acute wounds treated in a wound expertise centre

- with these predicting factors the time to complete healing can be estimated, based on our prediction formula

- this may help timely detection and referral of acute wounds that need extra attention to promote wound healing

nurses, sometimes concentrated in a wound expertise centre (WEC) (2). The idea behind these WECs is that a more concerted and dedicated care would bundle available expertise and evidence as to wound care and, thus, improve quality and efficiency in the chain of clinical, outpatient and home wound care (3). Furthermore, WECs would counteract unwanted variation due to the huge number of wound products on the market and inter-professional variation among caregivers $(4,5)$, despite available evidence regarding the treatment of a wide range of wound types (6). In the Netherlands, more than 20 WECs within and outside hospitals have now been launched, based on referral and care agreements among general practitioners, clinical specialists and wound care or home care nurses.

To appreciate which patients with wounds need advanced professional care, it would be helpful to know beforehand which wounds may heal poorly. To date, health care professionals, policymakers and researchers use prognostic models to identify variables that are influential in predicting patients at risk and for clinical decision making (7). Evidence from such prognostic models can help health care professionals to better advise their patients and to evaluate new prognostic variables in the context of existing knowledge (8).

In wound care, prognostic models have been developed to predict wound healing in chronic ulcers $(9-13)$, but not yet for acute, complex wounds. This is desirable because acute wounds occur more frequently than chronic wounds (14). Furthermore, even though most of these acute wounds heal without difficulty, many of these wounds can be subjected to factors that impede healing, for example, due to infection, damage to the vasculature or concomitant systemic disorders. This makes it hard to apply chronic wound models to acute wounds. Hence, it is important to know the factors that may predict a compromised healing of complex wounds, such as those treated in a WEC. This predictive modelling requires a comprehensive registry, which is kept by most WECs.

Therefore, the aim of this study was to investigate which factors best predict time to wound healing, regardless of the dressing materials or treatments used, in patients with complex acute wounds treated in a WEC. This may help caregivers to better inform and treat their wound patients, and to give input for the development of better wound treatments, in particular for those who are likely to have a protracted wound healing.

\section{Methods}

We based the description of our methods and results on the Quality in Prognosis Studies (QUIPS) tool (15). Our institutional medical ethics committee waived the need for approval for this study as it had no impact on the patients and their treatment, and data collection and analysis were performed anonymously.

For the purpose of this study, we employed the registry of the Mitralis Expertise Centre for Wound care in Heerlen, the Netherlands. This is an independent, nurse-led, outpatient expertise centre run by 20 nurse practitioners and specialised wound care nurses. These nurses followed postgraduate education in wound care on bachelor or master levels. This WEC treats about 1400 patients with refractory wounds yearly, referred from regional hospitals and general practitioners.

Their registry (Woundmonitor ${ }^{\circledR}$, SoftwarePartners Zuid BV, Heerlen, the Netherlands) was developed as an electronic patient data management system. This online software program contains data on patient characteristics, wound characteristics and documentation of wound care regimens, applied during the wound treatment period in the WEC. The registry is populated routinely by the nurses during the first patient visit. Factors related to wound healing were also assessed and entered at the first consultation. Data have been collected since the inception of the WEC in 2007.

Our dataset was extracted from this registry and contained data from patients treated between November 2007 and April 2012. We included patients with any type of wound with an acute aetiology, that is, after trauma or surgery. We excluded wounds due to arterial or venous insufficiency, pressure sores or malignancy, and diabetic foot ulcers. From patients with more than one wound, we randomly selected only one wound, under the condition that the baseline data were complete. Patients with a recorded treatment period of less than 7 days, that is, in which no meaningful treatment could have been given in the WEC, or without recorded baseline characteristics were excluded. Primary outcome was the time to complete wound healing after first assessment in the WEC.

The choice of potentially prognostic factors was based on data from the literature $(10,11,16)$ and suggestions made by a national expert panel, consisting of 16 specialised wound care nurses and 1 physician-'woundologist' in the Netherlands. The expert panel completed an online questionnaire, using a commercially available online survey tool (http://www.surveymonkey.com), about which factors they rated as most predictive of wound healing.

\section{Data analysis}

Data coding and analysis were performed using IBM SPSS statistics software (version 20.0.0.1, IBM, Armonk, NY). Possible predictive factors as proposed by the literature and the expert panel were analysed for their association with wound healing. Continuous factors were not categorised or dichotomised. To determine which of these factors best predict time to complete wound healing, a Cox proportional hazards regression analysis was chosen (17). Potentially predictive factors were entered into the model only if at least ten events were recorded per factor (18).

First, we checked the proportional hazards assumption for the possible predictive factors using log-minus-log plots. If a factor seemed non-proportional, we tested whether the factor 
had different effects in different groups, and whether an interaction existed between the time variable and the factor.

We detected significant independent prognostic factors through a multiple backward Cox regression analysis. Possible prognostic factors were removed one by one in order of the weakness of their multivariable association with the time to complete wound healing. Some prognostic factors (i.e. diabetic mellitus) were considered commonly accepted predictors and were therefore kept in the model. The impact of a prognostic value was expressed as a hazard ratio (HR), that is, change in the odds (hazard) of wound healing in relation to the size of the factor. Values larger than one indicate a beneficial effect of the factor on wound healing, whereas values below 1 indicate a detrimental effect. The significance level was set at $0 \cdot 05$.

As a measure of the predictive power of the regression model as to eventual wound healing, we calculated Harrell's $\mathrm{C}$-parameter. This parameter expresses the error rate, that is, the percentage of healed wounds with a higher risk profile to heal according to the model than the wounds that did not heal (19).

Finally, we performed a linear regression analysis after $\log$ transformation of the healing time as dependent factor to generate a formula to calculate the expected time to wound healing using the predicting factors as derived from the Cox regression analysis.

\section{Results}

The database contained 1660 wounds in unique patients, recorded during the study period. Of these, 766 records were either non-acute wounds $(n=103)$ or had insufficient data ( $n=663$ ) on the duration and time to healing of the wound and were therefore excluded. The baseline data had not been entered for 248 wound patients and a further 83 wounds had not received any treatment in the WEC. Hence, these were also excluded, leaving a total of 563 wounds for analysis in the final database.

Demographics of included patients and wounds are summarised in Table 1. The patients' wounds existed for a mean of 7 weeks before referral to the WEC. Most wounds were located on the leg $(52 \%)$ or on the trunk $(39 \%)$. During the study period, $455(81 \%)$ wounds had healed.

The final set of most important potential prognostic factors derived from the literature and group of experts is shown in Table 2. These factors comprised 15 patient characteristics and 7 wound characteristics, of which 4 were not available in the registry. Univariable regression analysis showed eight significant factors, as shown in Table 2. All available factors were entered in a multivariable Cox regression analysis, for which 368 of 563 patients were available owing to missing values for one or more variables for some patients. The PUSHtool was excluded from this analysis as it combines several wound characteristics already present in the model. No timedependent factors were introduced as covariate.

Table 3 shows the final model with six independent prognostic factors for the time to complete wound healing: the patient's age, the location, duration and size of the wound, and the presence of more than one sign of a wound infection.
Wound characteristics had the greatest impact on wound healing. In contrast, diabetic patients did not seem to have a significantly longer wound healing time. Wounds located on the trunk had a significantly lower chance of healing (HR 0.565) than head or neck wounds. This means that, at any given time point, the chance of healing of a trunk wound is 0.565 times lower than a wound in another area. The vast majority of these trunk wounds comprised larger, open abdominal wounds after surgery, $10 \%$ of which were drained intra-abdominal abscesses or fistulae. For continuous outcomes like wound size, the HR of 0.993 indicates that each additional square centimetre in size decreases the chance of wound healing with $0.7 \%$.

The error rate of the model, based on Harrell's C-parameter, was intermediate, $41 \%$. Using the total wound healing time rather than the treatment period in the WEC until wound healing did not yield different predictive factors.

Linear regression analysis showed an $R^{2}$ of 0.33 , that is, $33 \%$ of the variation in wound healing time could be explained by this model. The following formula could be derived to calculate time to complete wound healing for acute wounds, in which ' $\mathrm{e}$ ' is the base of the natural logarithm, with a value of approximately $2 \cdot 72$.

$$
\begin{aligned}
& \mathrm{e}^{\text {wound healing }} \text { (in days) }=4.12-0.005 * \text { age } \\
& +0.003 * \text { wound size }\left(\text { in } \mathrm{cm}^{2}\right) \\
& +0.001 *(\text { wound duration in days) } \\
& +0.41 \text { (if wound located on trunk) } \\
& +0.17 \text { (if infection present). }
\end{aligned}
$$

For example, a patient aged 50 with an acute, infected wound of $50 \mathrm{~cm}^{2}$ on the trunk, which already existed for 5 days before treatment, has a predicted time to complete wound healing of:

$$
\mathrm{e}^{4 \cdot 12-0 \cdot 25+0 \cdot 15+0 \cdot 005+0 \cdot 41+0 \cdot 17}=\mathrm{e}^{4 \cdot 605}=100 \text { days. }
$$

\section{Discussion}

This study shows that delayed healing of complex acute wounds treated in a WEC, as well as time to complete wound healing, can be predicted using simple patient and wound characteristics, available when the patients first present themselves at a WEC. The factors with the highest impact on wound healing were wound characteristics, among which the location on the trunk was the most significant, as well as clinical signs of wound infection. This suggests more attention and effort should be spent on an early treatment and prevention of wound infections, for which various options are available (20-23). Furthermore, large abdominal wounds may benefit from earlier referral to specialised wound care, for example, in a WEC. The clinical importance of age was, albeit significant, limited, as its hazard ratio was close to 1 , and cannot be influenced. The effect of having diabetes on the healing of these wounds was insignificant.

Previous research mainly focused on predictive models for chronic wounds. In pressure, venous and diabetic ulcers, ulcer size reduction was found to predict wound healing (24-26), but this could not be assessed until after 2 or 4 weeks of observation. In venous leg and diabetic foot ulcers, the size 
Table 1 Patient and wound characteristics at admission

\begin{tabular}{|c|c|c|c|c|}
\hline Characteristics & $N(\%)$ & Mean (SD) & Median (IQR) & Range \\
\hline \multicolumn{5}{|l|}{ Patient characteristics } \\
\hline Male gender & $223(40)$ & & & \\
\hline Age & & $66 \cdot 3(17.4)$ & $69.0(56.0-80.0)$ & $6-98$ \\
\hline $\mathrm{BMI}$ & & $27.4(6.5)$ & $26.4(23.4-29.9)$ & $14-66$ \\
\hline Smoking & $059(11)$ & & & \\
\hline Alcohol abuse & $12(2)$ & & & \\
\hline Drug addiction & $1(0.2)$ & & & \\
\hline \multicolumn{5}{|l|}{ Mobility } \\
\hline Independent & $267(59)$ & & & \\
\hline Walking aid & $139(31)$ & & & \\
\hline (Wheel) chair & $42(9)$ & & & \\
\hline Bedridden & $3(1)$ & & & \\
\hline \multicolumn{5}{|l|}{ General reasons for referral } \\
\hline (Complex) acute wound treatment & $425(66)$ & & & \\
\hline Negative pressure wound therapy & $138(22)$ & & & \\
\hline Diabetes mellitus & $113(20)$ & & & \\
\hline Cardiovascular disease & 218 (39) & & & \\
\hline Kidney disease & $15(3)$ & & & \\
\hline Use of corticosteroids & $31(6)$ & & & \\
\hline Nutritional status (unwanted $>5 \%$ weight loss, abnormal BMI or seriously ill) & $32(6)$ & & & \\
\hline \multicolumn{5}{|l|}{ Wound characteristics } \\
\hline \multicolumn{5}{|l|}{ Location } \\
\hline Leg & $230(52)$ & & & \\
\hline Trunk, armpit, groin & $172(39)$ & & & \\
\hline Arm, hand & $22(5)$ & & & \\
\hline Head, neck & $22(5)$ & & & \\
\hline Duration at admission (days) & & $49.9(93.8)$ & $19(6-46)$ & $0-740$ \\
\hline Duration until healed (days) & & $67.2(91.0)$ & $45(21-77)$ & $7-1200$ \\
\hline Size $\left(\mathrm{cm}^{2}\right)$ & & $17.9(32.1)$ & $6.0(1.8-19 \cdot 4)$ & $0.1-277$ \\
\hline Depth (cm) & & $0.8(2.0)$ & $0.0(0.0-0.5)$ & $0.1-12$ \\
\hline PUSH-tool score* & & $8.5(2.9)$ & $8.0(7.0-10 \cdot 0)$ & $3-16$ \\
\hline More than one sign of infectiont & $98(17)$ & & & \\
\hline Pain score (more than 4 on 10-point VAS) & $17(3)$ & & & \\
\hline Foul smell & $69(13)$ & & & \\
\hline Exudate (moderate or much) & $300(54)$ & & & \\
\hline
\end{tabular}

BMI, body mass index; VAS, visual analogue scale.

${ }^{*} \mathrm{PUSH}$-tool score is based on wound surface area, amount of exudate and wound appearance (30).

tBased on the Celsian signs: calor, rubor, dolor, tumor and function loss.

and duration of the wound were also predictive of an earlier wound healing $(11,12)$, which is similar to our findings.

We did not find an association between the presence of diabetes and delayed wound healing, which is a longstanding tenet (27). Apparently in acute wounds, particularly the abdominal wounds that usually have a better blood perfusion than leg wounds, this disorder has less impact on wound healing, as opposed to wounds with a chronic aetiology. Another reason could be that the patient population we investigated may have had an overall well-controlled glycaemia. The number of smokers in this study was relatively low, which may explain why we did not find an association with poor wound healing, although this is an acknowledged relationship (28).

Some limitations of this study need to be mentioned. First, in our patient sample, the more complex wounds may have been overrepresented owing to selection of patients referred to this WEC. This might have biased the outcomes of this prognostic study. On the other hand, it may have increased the prevalence of otherwise infrequent predictive factors. Second, the validity of this retrospective study depends on the accuracy of the WEC's registry and the completeness and uniformity of the data the personnel collects. The software program used by the WEC facilitates this and undergoes regular improvement updates. However, the registry was not primarily designed for research purposes. On the basis of our findings during this study, we suggested several improvements for this registry to allow more robust wound research in the future. Third, study validity was also influenced by the missing values in our model, but it is unlikely that missing values occurred more often in either quicker or slower healing wounds. Rather, these omissions probably occurred in the initial, learning phase of the registry or in times of higher workload, and therefore did not bias our results substantially. Fourth, not all potentially relevant data could be retrieved or analysed. The aetiology of the wound and previous treatments were not always clear, while the types of treatment and dressings used by the WEC and medication during the wound healing process changed irregularly. On the other hand, treatment regimens were according to best local practice and are therefore not likely to impede wound healing. These four limitations may 
Table 2 Potentially prognostic factors based on literature and questionnaire and univariable regression analysis

\begin{tabular}{|c|c|c|c|}
\hline Factor & Univariable Cox regression $P$-value & HR for wound healing & $95 \% \mathrm{Cl}$ \\
\hline \multicolumn{4}{|l|}{ Patient characteristics } \\
\hline Age & 0.016 & 1.008 & $1.001-1.014$ \\
\hline Gender & 0.390 & 1.087 & $0.898-1.316$ \\
\hline Race & n.a. & & \\
\hline Mobility & 0.427 & 1.046 & $0.938-1.167$ \\
\hline \multicolumn{4}{|l|}{ Nutritional status } \\
\hline BMI & 0.026 & 0.983 & $0.968-0.998$ \\
\hline Nutritional score & 0.367 & $1 \cdot 119$ & $0.877-1.428$ \\
\hline Smoking & 0.781 & 0.958 & $0.707-1.297$ \\
\hline Alcohol abuse & 0.938 & 1.027 & $0.530-1.988$ \\
\hline Drug addiction & * & & \\
\hline Use of corticosteroids & 0.336 & 0.823 & $0.554-1.224$ \\
\hline Diabetes mellitus & 0.328 & 0.888 & $0.701-1.126$ \\
\hline Cardiovascular diseases & 0.115 & $1 \cdot 165$ & $0.963-1.410$ \\
\hline Kidney disease & 0.646 & 0.874 & $0.492-1.552$ \\
\hline Seriously ill patient & $*$ & & \\
\hline ICU stay & n.a. & & \\
\hline Incontinence & n.a. & & \\
\hline \multicolumn{4}{|l|}{ Wound characteristics } \\
\hline Duration of the wound (from inception to presentation at WEC) & 0.001 & 0.998 & $0.997-0.999$ \\
\hline \multicolumn{4}{|l|}{ Location } \\
\hline Head/neck versus leg & 0.613 & $1 \cdot 144$ & $0.679-1.925$ \\
\hline Arm versus leg & 0.188 & 0.705 & $0.419-1.187$ \\
\hline Trunk versus leg & $<0.001$ & 1.692 & $1.375-2.082$ \\
\hline Size & $<0.001$ & 0.992 & $0.987-0.996$ \\
\hline Depth & $<0.001$ & 0.912 & $0.872-0.955$ \\
\hline More than one sign of infection ${ }^{\dagger}$ & 0.004 & 0.689 & $0.535-0.887$ \\
\hline PUSH-tool (30) & $<0.001$ & 0.907 & $0.877-0.938$ \\
\hline Percentage change in wound area over time & n.a. & & \\
\hline
\end{tabular}

$\mathrm{BMI}$, body mass index; $\mathrm{Cl}$, confidence interval; HR, hazard ratio; ICU, intensive care unit; n.a., not available data; WEC, wound expertise centre.

* Not included because less than ten events were recorded per factor.

tBased on the Celsian signs: redness, swelling, pain, warmth and function loss.

Table 3 Final model with significant independent predictive factors for wound healing derived from the multivariable Cox regression analysis

\begin{tabular}{|c|c|c|c|c|c|c|c|c|}
\hline & \multirow[b]{2}{*}{$B$} & \multirow[b]{2}{*}{ SE } & \multirow[b]{2}{*}{ Wald } & \multirow[b]{2}{*}{$d f$} & \multirow[b]{2}{*}{$P$-value* } & \multirow[b]{2}{*}{$\operatorname{Exp}(B)^{\dagger}$} & \multicolumn{2}{|c|}{$95 \% \mathrm{Cl}$ for $\operatorname{Exp}(B)$} \\
\hline & & & & & & & Lower & Upper \\
\hline Age & 0.009 & 0.004 & 5.420 & 1 & 0.020 & 1.009 & 1.001 & 1.018 \\
\hline Diabetes & 0.142 & 0.158 & 0.814 & 1 & 0.367 & $1 \cdot 153$ & 0.847 & 1.570 \\
\hline Wound duration & -0.002 & 0.001 & 8.023 & 1 & 0.005 & 0.998 & 0.996 & 0.999 \\
\hline Wound size & -0.007 & 0.002 & $10 \cdot 143$ & 1 & 0.001 & 0.993 & 0.988 & 0.997 \\
\hline Wound infection & -0.318 & 0.158 & 4.057 & 1 & 0.044 & 0.728 & 0.534 & 0.991 \\
\hline \multicolumn{9}{|l|}{ Wound location } \\
\hline Leg versus head/neck & -0.162 & 0.159 & 1.033 & 1 & 0.310 & 0.851 & 0.623 & 1.162 \\
\hline Trunk versus head/neck & -0.571 & 0.170 & 11.316 & 1 & 0.001 & 0.565 & 0.405 & 0.788 \\
\hline Arm versus head/neck & 0.132 & 0.403 & 0.107 & 1 & 0.743 & 1.141 & 0.518 & 2.514 \\
\hline
\end{tabular}

$\mathrm{Cl}$, confidence interval.

$\dagger \operatorname{Exp}(B)=$ hazard ratio; values above 1 indicate a beneficial effect of the factor on wound healing, whereas values below 1 indicate a detrimental effect.

*P-values of significant factors are shown in bold.

have caused the relatively high error rate of the model. Lastly, external validation of our study results is needed to appreciate the implications for wound care on a larger scale, as the study was performed in a specific cohort of patients treated in a WEC. Hence, these results are not necessarily the same for settings other than a WEC. A prospective study that predefines the factors and outcomes of interest may give more insight in the general applicability of our results.
The purported advantage of treating (complex) wounds in a WEC is still under debate. In a previous study, wound treatment in a WEC was not found to be a prognostic factor for wound healing $(11,29)$. On the other hand, the multidisciplinary, evidence-based treatment of complex wounds is likely to counteract practice variation and improve quality of wound care. In the Netherlands, a national set of criteria and indicators has been formulated for current or starting WECs to 
warrant the quality of their care. Also, if the registry of a WEC is accurate, this may help detect prognostic factors and timely treatments for (impaired) wound healing of more or less complex acute wounds.

\section{Acknowledgements}

We are grateful for the assistance of Frits Boonstra, Financial Director of Mitralis, and Maria Fuchs, Director of SoftwarePartners Zuid, and the personnel of the Mitralis Expertise Centre. We also thank Mrs B. Boogert, Mrs P.E. Broos-van Mourik, Mr P. Quataert, Mr A. Rondas and Mrs K. Timm for their contribution to the expert panel. No specific grant was received from any funding agency in the public, commercial or not-for-profit sectors. The authors report no conflicts of interest.

\section{References}

1. Ferreira MC, Tuma P Jr, Carvalho VF, Kamamoto F. Complex wounds. Clinics (Sao Paulo) 2006;61:571-8.

2. Gottrup F, Holstein P, Jørgensen B, Lohmann M, Karlsmar T. A new concept of a multidisciplinary wound healing center and a national expert function of wound healing. Arch Surg 2001;136:765-72.

3. Kim PJ, Evans KK, Steinberg JS, Pollard ME, Attinger CE. Critical elements to building an effective wound care center. J Vasc Surg 2013;57:1703-9.

4. Eskes AM, Storm-Versloot MN, Vermeulen H, Ubbink DT. Do stakeholders in wound care prefer evidence-based wound care products? A survey in the Netherlands. Int Wound J 2012;9:624-32.

5. Geary PM, Tiernan E. Management of split skin graft donor sitesresults of a national survey. Clin Plast Surg 2012;39:77-84.

6. Brölmann FE, Ubbink DT, Nelson EA, Munte K, van der Horst $\mathrm{CM}$, Vermeulen $\mathrm{H}$. Evidence-based decisions for local and systemic wound care. Br J Surg 2012;99:1172-83.

7. Moons KG, Royston P, Vergouwe Y, Grobbee DE, Altman DG. Prognosis and prognostic research: what, why, and how? BMJ 2009;338:b375.

8. Hemingway H, Riley RD, Altman DG. Ten steps towards improving prognosis research. BMJ 2009;339:b4184.

9. Margolis DJ, Berlin JA, Strom BL. Risk factors associated with the failure of a venous leg ulcer to heal. Arch Dermatol 1999;135:920-6.

10. Margolis DJ, Berlin JA, Strom BL. Which venous leg ulcers will heal with limb compression bandages? Am J Med 2000;109:15-9.

11. Margolis DJ, Allen-Taylor L, Hoffstad O, Berlin JA. Diabetic neuropathic foot ulcers: predicting which ones will not heal. Am J Med 2003;115:627-31.

12. Margolis DJ, Allen-Taylor L, Hoffstad O, Berlin JA. The accuracy of venous leg ulcer prognostic models in a wound care system. Wound Repair Regen 2004;12:163-8.
13. Schoonhoven L, Grobbee DE, Donders AR, Algra A, Grypdonck $\mathrm{MH}$, Bousema MT, Schrijvers AJ, Buskens E. Prediction of pressure ulcer development in hospitalized patients: a tool for risk assessment. Qual Saf Health Care 2006;15:65-70.

14. Franz MG, Steed DL, Robson MC. Optimizing healing of the acute wound by minimizing complications. Curr Probl Surg 2007;44:691-763.

15. Hayden JA, Cote P, Bombardier C. Evaluation of the quality of prognosis studies in systematic reviews. Ann Intern Med 2006; 144:427-37.

16. Bours GJ, De Laat E, Halfens RJ, Lubbers MJ. Prevalence, risk factors and prevention of pressure ulcers in Dutch intensive care units. Intensive Care Med 2001;27:1599-605.

17. Royston P, Moons KG, Altman DG, Vergouwe Y. Prognosis and prognostic research: developing a prognostic model. BMJ 2009;338:b604.

18. Mallett S, Royston P, Dutton S, Waters R, Altman DG. Reporting methods in studies developing prognostic models in cancer: a review. BMC Med 2010;8:20.

19. Harrell FE, Lee KL, Mark DB. Multivariate prognostic models: issues in developing models, evaluating assumptions and adequacy, and measuring and reducing errors. Stat Med 1996;15:361-87.

20. Ubbink DT, Vermeulen H, Lubbers MJ, Voss A. Antiseptics to prevent or treat wound infections; myths and evidence. Ned Tijdschr Geneeskd 2009;153:B328.

21. Storm-Versloot MN, Vos CG, Ubbink DT, Vermeulen H. Topical silver for preventing wound infection. Cochrane Database Syst Rev 2010;3:CD006478.

22. Vermeulen H, Westerbos SJ, Ubbink DT. Benefit and harm of iodine in wound care: a systematic review. J Hosp Infect 2010;76:191-9.

23. Anonymous. Wound infection in clinical practice. An international consensus. Int Wound J 2008;5(Suppl 3):iii-11.

24. van Rijswijk L, Polansky M. Predictors of time to healing deep pressure ulcers. Ostomy Wound Manage 1994;40:40-2, 44, 46-8 passim.

25. Kantor J, Margolis DJ. A multicentre study of percentage change in venous leg ulcer area as a prognostic index of healing at 24 weeks. Br J Dermatol 2000;142:960-4.

26. Sheehan P, Jones P, Giurini JM, Caselli A, Veves A. Percent change in wound area of diabetic foot ulcers over a 4-week period is a robust predictor of complete healing in a 12-week prospective trial. Plast Reconstr Surg 2006;117(7 Suppl):239S-44S.

27. Terranova A. The effects of diabetes mellitus on wound healing. Plast Surg Nurs 1991;11:20-5.

28. Silverstein P. Smoking and wound healing. Am J Med 1992;93(1A):22S-4S.

29. Margolis DJ, Allen-Taylor L, Hoffstad O, Berlin JA. Diabetic neuropathic foot ulcers: the association of wound size, wound duration, and wound grade on healing. Diabetes Care 2002;25:1835-9.

30. Hon J, Lagden K, McLaren AM, O'Sullivan D, Orr L, Houghton PE, Woodbury MG. A prospective, multicenter study to validate use of the PUSH in patients with diabetic, venous, and pressure ulcers. Ostomy Wound Manage 2010;56:26-36. 